\title{
Preparation and Characterization of Highly Transparent Conducting Composites Consisting of Acid-Doped Poly(o-toluidine) and Poly(methyl methacrylate)
}

\author{
Rahul C. PAtiL, Seddique M. Ahmed, and Kotaro OGURA ${ }^{\dagger}$ \\ Department of Applied Chemistry, Faculty of Engineering, Yamaguchi University, \\ Tokiwadai, Ube 755-8611, Japan
}

(Received April 12, 1999)

\begin{abstract}
Composites consisting of camphor sulfonic acid (CSA)-doped poly(o-toluidine) (POT) and insulating poly(methyl methacrylate) (PMMA) show percolation behavior and the value of percolation threshold to be 4 wt\% of conducting CSA-doped POT. The composite was considerably transparent, e.g., the transmittance of the composite $(\sim 15$ um) with $4 \%$ of CSA-doped POT and $96 \%$ of PMMA was about $70 \%$ at $540 \mathrm{~nm}$. Conductivity at the percolation threshold point is attributed to the interconnected network, which was revealed by scanning tunneling micrographs. Thermogravimetric analysis demonstrates four step decomposition and phase separated morphology of CSA-doped POT is found to be thermodynamically stable up to $250^{\circ} \mathrm{C}$. This was supported by mass spectra simultaneously recorded in thermal analysis.
\end{abstract}

KEY WORDS Poly(o-toluidine)/Conductivity / Transparent / Percolation Threshold / Interconnected

Network /

The use of neat conducting polymers in various technological applications has been restricted due to their poor mechanical properties. This problem has been solved by combining electronic properties of conducting polymers with mechanical properties of insulating polymers. This is a unique combination which seems to have great potential for many applications. The use of selected sulfonic acids, ${ }^{1-3}$ and phosphoric acid diesters ${ }^{4,5}$ as protonating agents makes it possible to process conducting polymers from solution.

Although several reports are available on various composites processed either from solution ${ }^{3,6,7}$ or by thermal blending, ${ }^{8-10}$ there are few works on electrically conducting transparent composites. ${ }^{11,12}$ Such composites are especially important in applications for electrostatic dissipation (ESD)/antistatic, optically transparent electrode and corrosion protection. ${ }^{11-13}$ These composites could serve for more than just delivering two properties (conductivity and transparency), in visual application such as electrochromic indicator or sensing material. ${ }^{13}$ The need of transparent coating is probably caused by brittleness, humidity-dependence, and poor long-term performance of the existing materials (ITO, ceramic powders etc.).

Cao et al. first prepared optically transparent film by mixing polyaniline with poly(methyl methacrylate) (PMMA). ${ }^{12}$ The electrical conductivity of their composite at about $5 \%$ of conductive component was $10 \mathrm{~S} \mathrm{~cm}^{-1}$. Poly(o-toluidine) (POT)/PMMA composite seems to be a candidate for an useful transparent coating, however, to the best of our knowledge no reports are available for such composite. The present work attemptes to apply the composite of camphor sulfonic acid (CSA)-doped POT and PMMA to the optically transparent and conductive film. The composite was characterized by optical absorption and fourier transform infra-red spectroscopy (FTIR), scanning tunneling microscopy (STM), thermogravimetric analysis/mass spectroscopy (TG/MS), and electri-

\footnotetext{
${ }^{\dagger}$ To whom correspondence should be addressed.
}

cal conductivity method.

\section{EXPERIMENTAL}

All chemicals used were of analytical reagent grade. The emeraldine base of POT was synthesized using earlier described procedure. ${ }^{14}$ The dried fine powder of emeraldine base (EB) was mixed with $d, l$ camphorsulfonic acid at a molar ratio of $1: 2$ for EB (tetramer) to CSA using an agate mortar and pestle in an inert atmosphere. A given amount of CSA-doped POT was dissolved in $m$ cresol under ultrasonic irradiation for $1 \mathrm{~h}$ at $50^{\circ} \mathrm{C}$ to prepare $4 \mathrm{wt} \%$ solution. The resulting viscous deep green solution was further utilized for preparing the composites. To obtain composite solutions, the required proportion of CSA-doped POT was mixed with $10 \mathrm{wt} \%$ solution of PMMA at room temperature. The composite was casted on a glass plate using a spin coater unit (Oriental Motor Co. Ltd., Japan) at a rotating speed of $1000 \mathrm{rpm}$, and dried on a hot plate in order to evaporate the solvent. Film thickness was measured with a Hitachi S2300 scanning electron microscope.

Transmittance measurements were carried out on a Shimadzu double beam spectrophotometer (model 2200). IR spectra of doped and undoped forms of CSA-doped $\mathrm{POT}$ in $\mathrm{KBr}$ pellets were recorded using a Shimadzu FT-IR (Type $8100 \mathrm{M}$ ) spectrometer. The conductivity of the films was determined by the two probe method using Hokuto Denko galvanostat (Model, HA-501). TG/MS analysis was performed on a JEOL MS-TG/DTA (model 220) under helium atmosphere at a scan rate of $5^{\circ} \mathrm{C} \min ^{-1}$. The STM image was taken using a Nanoscope II instruments from Digital Instruments. Samples were prepared by casting the composite solution on a steel plate and by evaporating the solvent at $50^{\circ} \mathrm{C}$. The measurements were performed in a constant current mode with a bias voltage of $30.0 \mathrm{mV}$ and tunneling current $2.0 \mathrm{nA}$. All images in the text are real time photographs taken directly from the computer screen. 

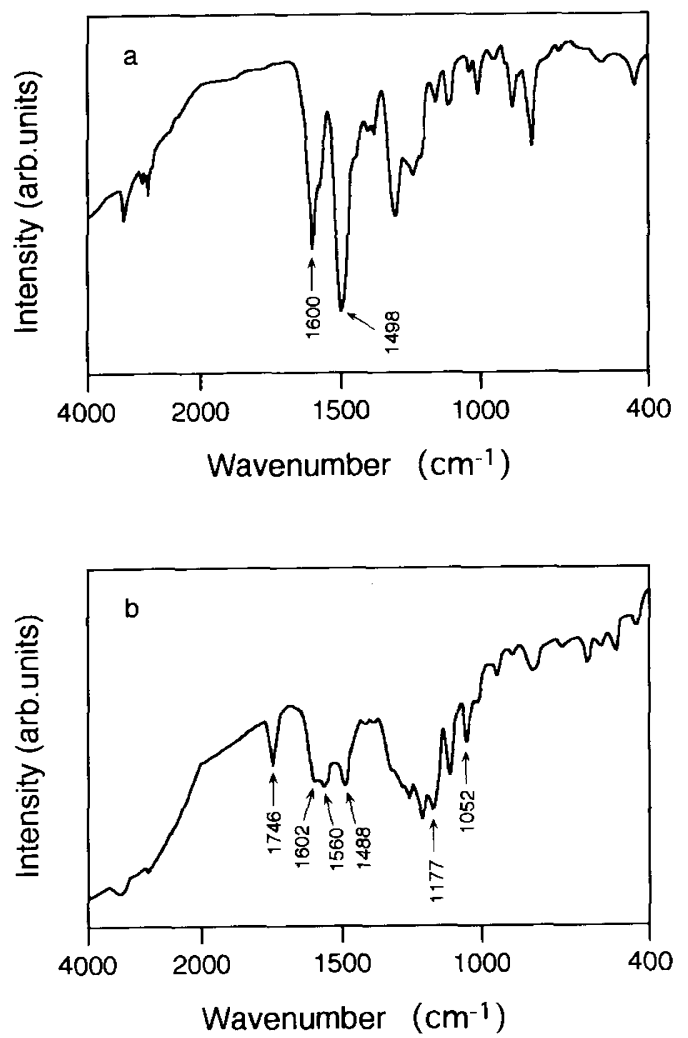

Figure 1. IR absorption spectra of (a) EB (POT) and (b) CSAdoped POT.

\section{RESULTS AND DISCUSSION}

Protonation of the base form of the POT was proved with the help of IR spectroscopy. Figures $1 \mathrm{a}$ and $1 \mathrm{~b}$ show the IR spectra of the base and protonated forms of POT, respectively. The key bands in the base form match well with those reported in the literature. ${ }^{15}$ In comparison of IR spectra of the base with that of the protonated form, two prominent features reflecting the protonation of the base form are seen clearly. The red shift in the quinoid (from 1600 to $1560 \mathrm{~cm}^{-1}$ ) and benzenoid vibrations (from 1498 to $1488 \mathrm{~cm}^{-1}$ ) are indicative of delocalization of quinoid and benzenoid structures to the semiquinoid form (polaron), confirming the protonation of the emeraldine base. ${ }^{16}$ The absorption bands at 1602 and 1177 $\mathrm{cm}^{-1}$ can be ascribed to the Raman active $\mathrm{C}=\mathrm{C}$ ring stretching vibration and an $\mathrm{a}_{\mathrm{g}} \mathrm{C}-\mathrm{H}$ in plane ring deformation or an $\mathrm{a}_{\mathrm{g}}$ ring amine stretching vibrations, respectively. ${ }^{17}$ These bands are normally IR-inactive, but become IR-active when a protonation process is accompanied by confirmational changes in the polymer chain, i.e., the formation of polaron and bipolaron. Hence, the appearance of these bands for the doped polymer provides an evidence for the protonation of the polymer. The presence of well-defined peaks in the doped form at 1746 and $1052 \mathrm{~cm}^{-1}$, relating to $\mathrm{C}=\mathrm{O}$ and $\mathrm{SO}_{3}{ }^{-}$groups, shows the incorporation of $\mathrm{CSA}^{-}$ions into the polymer backbone.

To provide additional support to the IR data, the optical absorption spectrum of CSA-doped POT dissolved in $m$-cresol was recorded. Optical absorption spectrum of

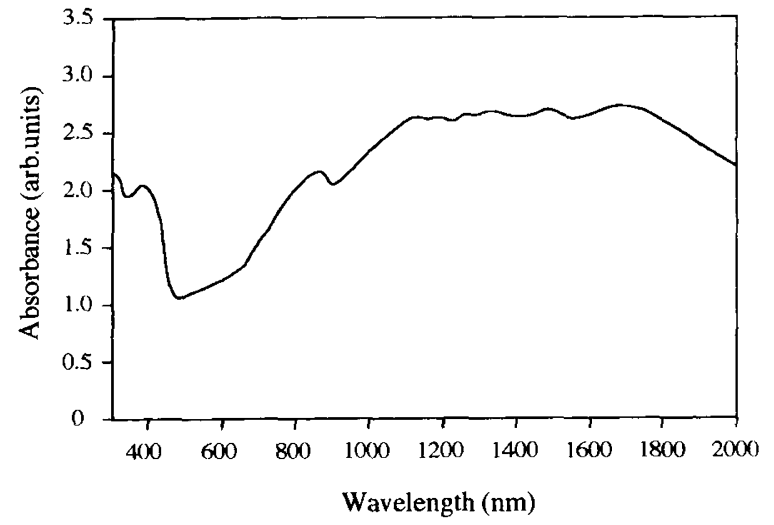

Figure 2. Optical absorption spectrum of CSA-doped POT in $m$ cresol.

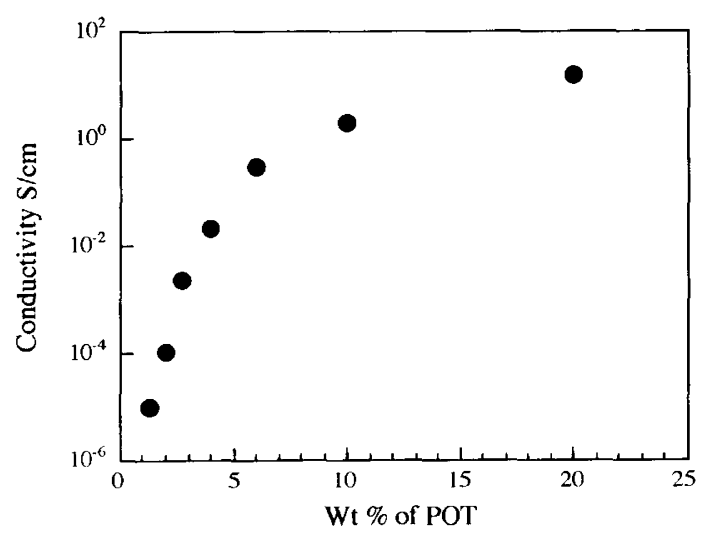

Figure 3. Plot of conductivity against wt\% of CSA-doped POT in the PMMA matrix.

this polymer in the range between 300 and $2000 \mathrm{~nm}$ is shown in Figure 2. The appearance of free carrier tail at $\sim 1000 \mathrm{~nm}$ is indicative of change in polymer conformation from coil to expanded coil like. This transformation in conformation facilitates delocalization of electrons through polymer chain effectively by reducing conjugation defects. The optical absorption spectrum is in well agreement with the conductivity value of CSA-doped POT which is found to be higher $\sim 28 \mathrm{~S} \mathrm{~cm}^{-1}$ compared to HCl-doped POT $\left(\sim 1 \mathrm{~S} \mathrm{~cm}^{-1}\right)$.

Variation in conductivity of the composite film with wt $\%$ of CSA-doped POT is presented in Figure 3. The composite exhibits reasonably high conductivity even at low content of CSA-doped POT, and the percolation threshold is at $\sim 4 \%$. Such a low percolation threshold can be explained with the help of STM studies. STM images of the composite containing $4 \%$ of CSA-doped POT are displayed in Figures $4 \mathrm{a}$ and $4 \mathrm{~b}$. As seen from Figure $4 \mathrm{a}$, the composite is very homogeneous and the contrast between darker and brighter regions is poor. Figure $4 \mathrm{~b}$ shows the STM image of the composite in which the insulating PMMA is completely dissolved in $\mathrm{CHCl}_{3}$. In this figure, the brighter region is due to the void formed by the removal of PMMA while the darker region represents the interconnected network of remaining conducting particles. The removal of PMMA from the composite was confirmed from the FT-IR measurements 
(a)

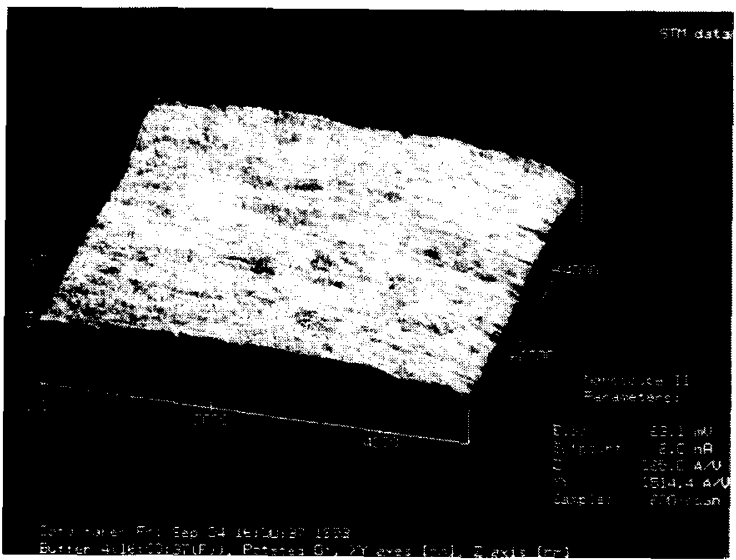

(b)

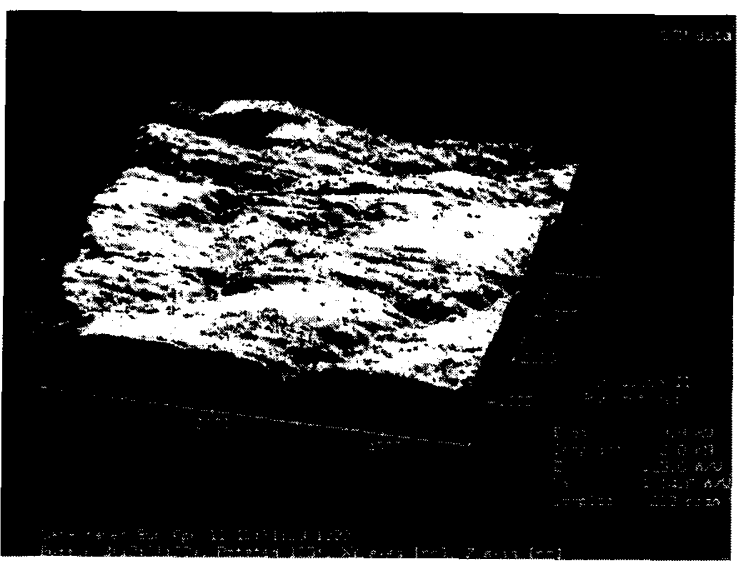

Figure 4. Scanning tunneling electron micrographs of the PMMA composite with (a) $4 \%$ of CSA-doped POT and (b) after etching (a) in $\mathrm{CHCl}_{3}$ for $12 \mathrm{~h}$.

of pure PMMA and that of PMMA extracted composite in reflectance mode. The prominent bands appearing due to PMMA especially at $2980,1720,1435,1387,1140$, and $1063 \mathrm{~cm}^{-1}$ disappeared in the PMMA extracted composite. The STM results are in well agreement with the conductivity data where the significant value of conductivity was observed at the percolation threshold. The interconnected network gave rise to a conductive path for electrons to travel from one end to other, resulting in the revelation of conductivity. Similar observation is reported for the PANI-PMMA composite by Heeger et al. ${ }^{18}$

The low percolation threshold is extremely important for the formation of transparent coating. Conductive polyaniline and its derivatives exhibit high extinction coefficients for blue and red lights, ${ }^{19}$ and the transparent films may be fabricated only at extremely low content of the conductive phase in the composite. Figure 5 shows the transmittance of visible light between 475 and 675 $\mathrm{nm}$ for the PMMA composites with different percentage of CSA-doped POT, where thickness was always $\sim 0.15$ $\mu \mathrm{m}$. Although transmittance decreases with increasing concentration of conducting particles, the composite containing $4 \%$ of CSA-doped POT still shows transmittance of about $70 \%$. Thus, unlike the composite with polyaniline, the CSA-doped POT/PMMA blend can serve well for the fabrication of transparent conductive coatings.

It is important to know the thermal properties of CSAdoped POT/PMMA in order to check its usefulness in certain applications where higher temperature process-

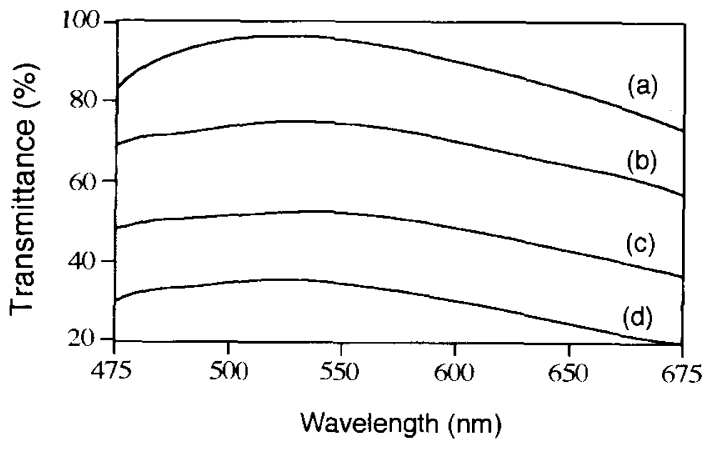

Figure 5. Transmission spectra of CSA-doped POT/PMMA composites at various concentrations of CSA-doped POT, (a) $1 \%$ (b) $4 \%$ (c) $10 \%$ and (d) $20 \%$.

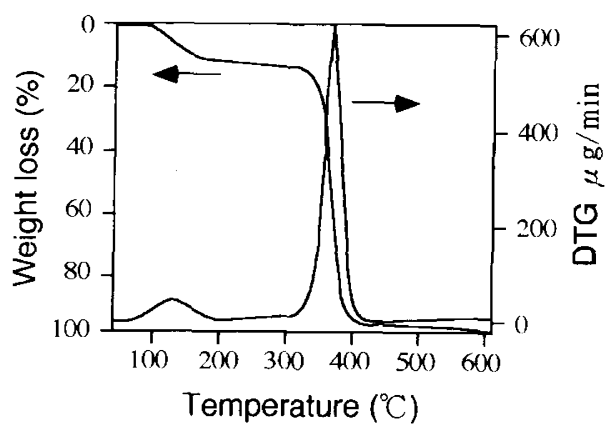

Figure 6. TG thermograms of the CSA-doped POT/PMMA composite. Heating scan rate, $5^{\circ} \mathrm{C} \mathrm{min}^{-1}$.

Table I. Details of decomposition of CSA-doped POT/PMMA blend

\begin{tabular}{|c|c|c|c|c|}
\hline \multirow{2}{*}{ Step } & \multirow{2}{*}{$\begin{array}{c}\text { Temperature } \\
\text { range } /{ }^{\circ} \mathrm{C}\end{array}$} & \multirow{2}{*}{$\frac{\text { Weight loss }}{\%}$} & \multirow{2}{*}{\multicolumn{2}{|c|}{ Fragments obtained $(\mathrm{m} / \mathrm{z})$}} \\
\hline & & & & \\
\hline 1st step & $40-200$ & 11.48 & \multicolumn{2}{|c|}{$\begin{aligned} 53 & : \mathrm{C}_{4} \mathrm{H}_{5} \\
79 & : \mathrm{C}_{6} \mathrm{H}_{6} \\
91 & : \mathrm{C}_{6} \mathrm{H}_{5} \mathrm{CH}_{3} \\
107 & : \mathrm{C}_{6} \mathrm{H}_{4} \mathrm{CH}_{3} \mathrm{OH}\end{aligned}$} \\
\hline 2nd step & $200-317$ & 3.33 & $\left.\begin{array}{c}41: \mathrm{C}_{3} \mathrm{H}_{5} \\
55: \mathrm{C}_{3} \mathrm{H}_{3} \mathrm{O} \\
69: \mathrm{C}_{4} \mathrm{H}_{5} \mathrm{O} \\
64: \mathrm{SO}_{2} \\
81: \mathrm{SO}_{3} \\
95: \mathrm{CH}_{2} \mathrm{SO}_{3} \\
109: \mathrm{C}_{8} \mathrm{H}_{13} \\
135: \mathrm{C}_{9} \mathrm{H}_{12} \mathrm{O} \\
152: \mathrm{C}_{10} \mathrm{H}_{15} \mathrm{O}\end{array}\right]$ & From PMMA \\
\hline 3rd step & $317-415$ & 81.86 & $\left.\begin{array}{r}41: \mathrm{C}_{3} \mathrm{H}_{5} \\
55: \mathrm{C}_{3} \mathrm{H}_{3} \mathrm{O} \\
69: \mathrm{C}_{4} \mathrm{H}_{5} \mathrm{O} \\
85: \mathrm{C}_{4} \mathrm{H}_{5} \mathrm{O}_{2} \\
100: \mathrm{C}_{5} \mathrm{H}_{8} \mathrm{O}_{2}\end{array}\right]$ & From PMMA \\
\hline 4th step & $415-600$ & 3.33 & $44: \mathrm{CO}_{2}$ & \\
\hline
\end{tabular}

ing is essential, e.g., in melt processing for packaging electronic materials. ${ }^{12}$ The temperature stability of interconnected network morphology has been investigated by the tunneling electron microscopic method. ${ }^{18}$ In the present work, the exact degradation path was demonstrated with the help of TG/MS spectra. Figure 6 represents the thermal pattern of CSA-doped POT/PMMA, showing four step degradation. The weight loss of $\sim 11.5 \%$ in the initial step is attributed to $m$-cresol sol- 

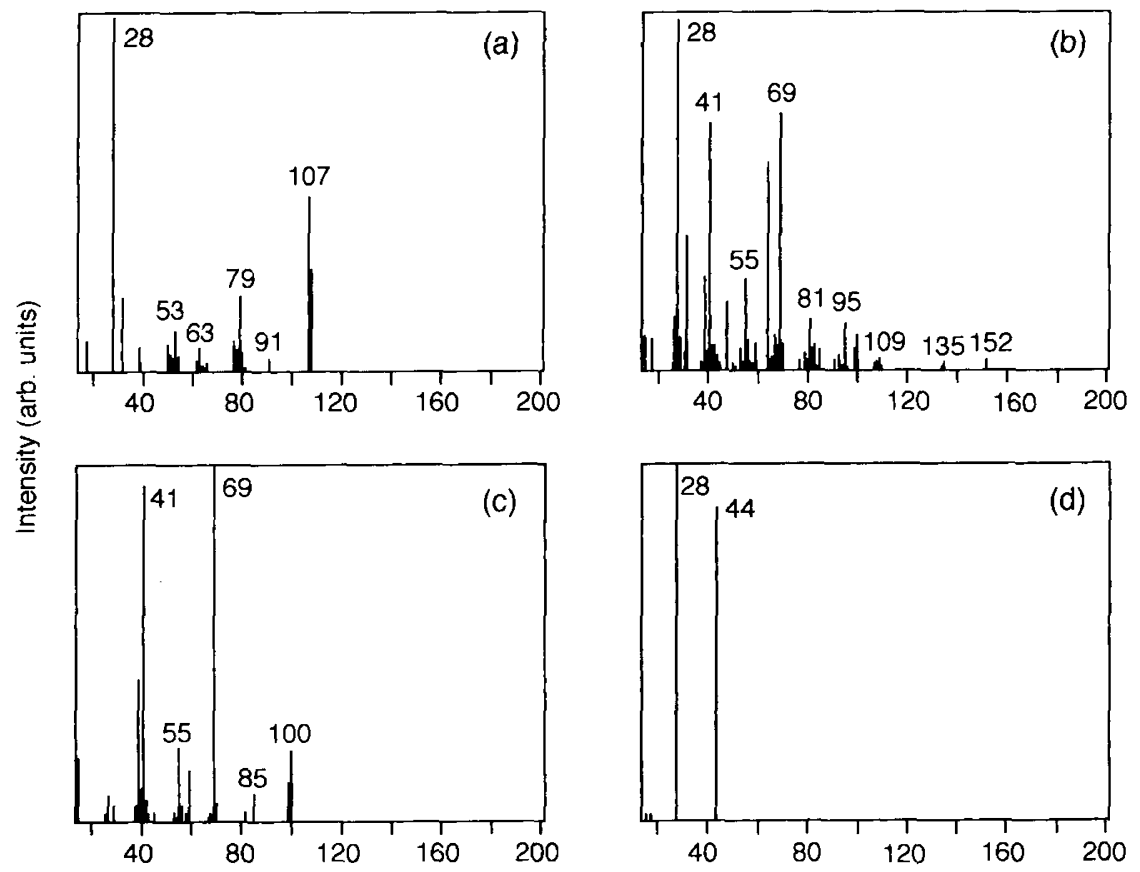

$M / Z$

Figure 7. Mass spectra of the CSA-doped POT/PMMA taken at different temperatures, (a) $120^{\circ} \mathrm{C}$, (b) $250^{\circ} \mathrm{C}$, (c) $390^{\circ} \mathrm{C}$, (d) $550^{\circ} \mathrm{C}$.

vent (Table I, Figure 7a). Before taking TG/MS spectra, the composites were preheated at $50^{\circ} \mathrm{C}$ for $48 \mathrm{~h}$ on a hot plate, and it is therefore surprising that $m$-cresol is involved in TG/MS analysis. The appearance of a significant amount of $m$-cresol even after heating at $50^{\circ} \mathrm{C} \mathrm{dem}$ onstrates the existence of strong hydrogen bonding between the $\mathrm{OH}$ group at meta position and the carbonyl group of CSA. This bonding may be weaken as temperature is raised to $120^{\circ} \mathrm{C}$, leading to loss of $m$-cresol. The second step between 200 and $317^{\circ} \mathrm{C}$ represents the loss of CSA together with the initiation of gradiation of conducting as well as insulating polymer (Table I). This step is accompanied by weight loss of $3.33 \%$. The mass spectra of CSA doped POT/PMMA composite recorded at 250 ${ }^{\circ} \mathrm{C}$ show purely the loss of CSA molecules together with the insulating PMMA. However, the spectra does not exhibit any single fragment from the main chain of the poly(o-toluidine) (Figure 7b). Hence, a small-scale deprotonation of the CSA-doped POT occurs around $130^{\circ} \mathrm{C}$, and proceeds slowly on further elevation of temperature. The CSA molecule does not vaporize until $200^{\circ} \mathrm{C}$, but remains localized within the POT network. ${ }^{20}$ Above $200^{\circ} \mathrm{C}$, CSA molecules become more mobile and finally detached from the polymer backbone. The decomposition of CSA molecules does not occur until $\sim 250^{\circ} \mathrm{C}$, and the network of POT remains intact in the insulating matrix, indicating that phase-separated network morphology is thermally stable. The third step extending up to $417^{\circ} \mathrm{C}$ suggests loss of PMMA matrix $(81.8 \%)$ as PMMA melts at $370^{\circ} \mathrm{C}$ (Table I, Figure 7c). Once PMMA is completely decomposed, the chains of POT undergo the decomposition $(3.33 \%)$ with the evolution of $\mathrm{CO}_{2}$ (Figure $7 \mathrm{~d}$ ).

\section{CONCLUSIONS}

The optically transparent composites can be prepared using substituted derivative of polyaniline like POT. The composite of CSA-doped POT with PMMA possesses reasonably good conductivity and is transparent as well. Such composite can be useful in certain applications such as antistatic coating in electronic industry where a visual inspection is necessary. The low percolation threshold for CSA-doped POT/PMMA composite is attributed to the formation of the thermally stable interpenetrating network which was confirmed from the STM observation. This observation may indicate that such composites can be fabricated by extrusion process which is commercially important.

Acknowledgments. One of the authors (RCP) thanks Venture Business Laboratory for providing PDF.

\section{REFERENCES}

1. J. Joo, Y. C. Chung, H. G. Song, J. S. Baeck, W. P. Lee, A. J. Epstein, A. G. MacDiarmid, S. K. Geong, and E. J. Oh, Synth. Met., 84, 739 (1997).

2. S. A. Chen and G. W. Hwang, J. Am. Chem. Soc., 117, 10055 (1995).

3. Y. Z. Wang, J. Joo, C. H. Hsu, and A. J. Epstein, Synth. Met., 68, 207 (1995).

4. W. Lunzy, T. Kaniowski, and A. Pron, Polymer, 39, 475 (1998).

5. J. Laska, K. Zak, and A. Pron, Synth. Met., 84, 117 (1997),

6. A. G. MacDiarmid and A. J. Epstein, Synth. Met., 65, 103 (1994).

7. R. C. Patil, K. Kuratani, M. Nakayama, and K. Ogura, J. Polym. Sci., Part A: Polym. Chem., 37 (1999) 2657.

8. E. Virtanen, J. Laakso, H. Ruohonen, K. Vakiparta, H. Jarvinen, M. Jussila, P. Passiniemi, and J. E. Osterholm, Synth. Met., 84, 113 (1997).

9. J. P. Yang, P. Rannou, J. Planes, A. Pron, and M. Nechtschein, Synth. Met., 93, 169 (1998).

10. A. Pron, W. Lunzy, and J. Laska, Synth. Met., 80, 191 (1996).

11. V. G. Kulkarni, Synth. Met., 71, 2129 (1995). 
12. Y. Cao, G. M. Treacy, P. Smith, and A. J. Heeger., Appl. Phys. Lett., 60, 2711 (1992).

13. B. Wessling, Synth. Met., 93, 143 (1998).

14. Y. Cao, P. Smith, and A. J. Heeger, Synth. Met., 32, 263 (1989).

15. Z. Ping, J. Chem. Soc., Faraday Trans., 92, 3063 (1996).

16. I. Harada, Y. Furukawa, and F. Ueda, Synth. Met., 29, E-303 (1989).
17. S. Quillard, G. Louarn, J. P. Buisson, S. Lefrant, J. Masters, and A. G. MacDiarmid, Synth. Met., 49-50, 525 (1992).

18. C. Y. Yang, Y. Cao, P. Smith, and A. J. Heeger, Synth. Met., 53, 293 (1993).

19. A. Pron, M. Zagorska, Y. Nicolau, F. Genoud, and M. Nechtschein, Synth. Met., 84, 89 (1997).

20. C. Y. Yang, M. Reghu, A. J. Heeger, and Y. Cao, Synth. Met., 79, 27 (1996). 